\title{
When Can Oil Economies be Deemed Sustainable?
}

\section{Giacomo Luciani and Tom Moerenhout}

When can oil economies be deemed sustainable? We did not expect to find an unequivocal and final answer to this question when we set out collecting the chapters of this book, and in fact do not believe that an unequivocal and final answer exists. Our more modest purpose was to question a stereotype - that all Gulf economies are not sustainable-and start a critical discussion of what these economies and polities should do to guarantee themselves a relatively stable future.

Unsurprisingly, the different authors that contributed to this collection manifest different sensitivities and lay their emphasis on various aspects,

G. Luciani (四)

Graduate Institute of International and Development Studies, Geneva, Switzerland

Paris School of International Affairs, Sciences Po, Paris, France

e-mail: giacomo.luciani@graduateinstitute.ch

T. Moerenhout

Columbia University, School of International and Public Affairs, New York, NY, USA

e-mail: tm2794@columbia.edu

(C) The Author(s) 2021

G. Luciani, T. Moerenhout (eds.), When Can Oil Economies Be

Deemed Sustainable?, The Political Economy of the Middle East, https://doi.org/10.1007/978-981-15-5728-6_14 
but points of convergence are not missing, and they are important. In this last chapter, we shall try to pull together some of the strings and propose at least some overall conclusions, on which further debate and research may be encouraged.

\section{The End of OIL}

The most immediate way in which the issue of sustainability of the oil economies is commonly framed is to point to the time when oil runs out.

There really is no case of an oil-producing country having completely run out of oil, but having faced declines, yes. That said, globally, since the end of the first decade of the current century, we have ceased worrying about peak oil supply — a presumed physically determined fate-and now discuss peak oil demand and unburnable carbon, that is, the possibility that oil may lose its economic value because of the energy transition. The potential impact of declining oil rents on government finance is highlighted in almost all chapters in the book:

there is an inescapable imperative to prepare for a world in which hydrocarbons are no longer the main source of revenue, even if there may be alternative ways to monetize hydrocarbon resources that do not contribute to global emissions-Al Saffar

However, there is also convergence on the view that the decline in oil rents will be a gradual phenomenon, and not a sudden one. On the one hand, global oil demand is likely to continue to be robust for a while, projected to increase at a compound annual average growth rate of $0.5 \%$ until 2040 (driven mainly by demand growth in India, China and the Middle East). On the other hand, oil-producing countries can also implement policies to resist or counter the process. On the first point, Fattouh and Sen write that a

key observation that can be drawn from the range of peak demand forecasts is that oil will continue to be an important part of the energy mix for the foreseeable future. The incumbent advantages of oil as an energy source, including its high energy density and an existing infrastructure ecosystem geared around it, imply that even if oil demand peaks, it is unlikely to 'fall off a cliff'.

If we reason on the basis of a 20-year time horizon-certainly a very long-term one for fiscal, monetary, industrial and indeed almost all 
policies - we should accept that, while the oil rent is likely to decline over this period of time, it will not disappear altogether. The speed with which the oil rent may decline is a function of volumes sold and prices obtained. These two aspects are interlinked and very much depend on policies of major oil-importing countries, investment decisions of major national and international oil companies, producer subsidy allocations in hydrocarbonrich countries and, more generally, how the economy will react to the combination of an energy transition and rising energy demand.

If the demand peak is driven by policies based on regulation or on imposing a high price on carbon, it is possible that supply may exceed demand and drive prices down. However, this is not the situation at the moment, and current concerns are rather that investment in the development of new oil sources may be insufficient to compensate for the natural decline of producing fields and unable to meet the still growing global demand. Therefore, the outlook may be one of growing, rather than declining, prices. The recent past has taught us that oil prices are on an unpredictable trajectory and that this uncertainty affects both investment in the sector and fiscal sustainability of many, but not all, producing countries. Limiting this volatility will be a key objective to secure a more stable oil rent (a point stressed by Manal Shehabi in Chap. 7).

Furthermore, a decline in global demand for hydrocarbons does not necessarily translate into a decline of demand for Gulf Cooperation Council (GCC) oil and gas exports. Hydrocarbons produced in the GCC are amongst the cheapest in the world, and there are strategies that the Gulf countries can adopt-and are adopting - to defend or increase their market share. On this point, several of our authors (notably Fattouh and Sen, Luciani and Krane) converge.

Fattouh and Sen believe that "As the world's lowest-cost oil producers, Arab oil-exporting countries will most likely be required to fill this gap", that is, the gap between investment required to meet expected future demand and what is actually being undertaken. Their main preoccupation is with the very significant investment effort required, as "any expansion in productive capacity will require massive investments running into billions of dollars". This in turn has political implications, because "Countries also require relatively stable political environments to make these investments. In the absence of such stability, it is possible that some countries with cheap reserves will be unable to develop these reserves".

On oil prices, they also stress the need for producing countries to have a proactive attitude towards coordination with major producers in other 
regions, beyond the temporary character of recent OPEC+ production decisions:

maintaining cooperation in a more competitive world is very challenging and while producers have the incentive to cooperate, the cooperation between producers has to take a different shape to what has existed in the past. For instance, producers should not only be concerned with low oil prices, but also be proactive when prices are too high, as high oil prices induce strong supply and demand responses and speed up the energy transition.

Krane elaborates on three possible alternative strategies that the producing countries may follow in order to defend their hydrocarbon exports, which he dubs "Dig in", "Join in" and "Throw in". The first alternative includes developing non-fuel uses for hydrocarbons, decreasing the carbon emissions related to their production, improving the efficiency of internal combustion engines and integrating vertically into the markets of major importing countries, notably in Asia. The second alternative focuses on carbon capture and sequestration, reduction of flaring and emissions of greenhouse gases (GHG) different from $\mathrm{CO}_{2}$ and promoting the uptake of non-carbon technologies, notably renewables and nuclear, to reduce the countries' own emissions. The last strategy envisages acceptance of global warming above endorsed goals in the Paris Agreement and is clearly not of the author's liking, but it pretty much corresponds to de facto behavior of all major emitting countries-whether we like it or not.

We find the same leading ideas expressed in other chapters of this book. Ali al Saffar writes about the need to "capture more value from hydrocarbons" and "using natural gas strategically in support of diversification goals", where he includes downstream integration and the development of petrochemicals. He also writes about "tapping the large, underutilized potential of renewables" and "phasing out subsidized use of energy" (the latter also the main focus of the chapter by Tom Moerenhout) to reduce domestic consumption of oil and redirect the same to exports. Finally, he advises "supporting the development of cleaner and more efficient energy technologies", where he includes Carbon capture, utilization and storage (CCUS). Similarly, Fattouh and Sen write: "Oil producers will need to be far more strategic in developing their energy sector, including the renewables sector, and strengthening forward and backward linkages to help diversify their economies".

Luciani supports essentially the same package of strategies, writing in particular about decarbonizing the production of oil, CCUS and 
integrating downstream toward non-fuel uses. He adds the perspective of the transition toward a hydrogen economy which would at least initially be based on producing hydrogen from hydrocarbons and capturing the resulting $\mathrm{CO}_{2}$, rather than only looking at more expensive methods of hydrogen sourcing out of electrolysis or other biomass-based technologies.

Thus our discussion allows us to place the issue of sustainability in a perspective of gradualism where hydrocarbons remain an essential component of the GCC economies' competitiveness for several decades, which is as far into the future as one may meaningfully discuss. None of the authors believe that hydrocarbons alone can guarantee sustainability, but the view that the Gulf economies are not sustainable because oil and gas will soon and rapidly lose all economic value is not supported by current market trends as well as medium-term projections. Neither of course it is proposed that Gulf oil producers can be passive and keep enjoying the rent: on the contrary, much initiative and adaptation will be needed to defend the rent. But losing access to the oil rent is neither an inescapable fate nor likely a sudden development.

\section{NEED FOR DiVERSIFICATION?}

Together with the belief that hydrocarbon rents may soon disappear, the discourse on sustainability is frequently associated with the need for economic diversification, that is, development of non-oil sectors, which is frequently interpreted as moving away from oil. In this view, all developments, either downstream or upstream from hydrocarbon production, are considered as doomed, since they depend on oil, which is expected to disappear. Unsurprisingly, when considering the trends and projections discussed earlier, our authors offer critical visions leading to a much more nuanced conclusion.

First of all, however, it is asserted that-contrary to the most widely accepted stereotype-diversification has already occurred. Luciani and Beutel both emphasize this point, based on different and complementary statistical evidence. Beutel, in particular, proposes a detailed analysis based on national accounts and input-output analysis, leading to some quite unexpected conclusions with respect to the degree of diversification of the Gulf economies, the pace of change and the international relativities - in particular with respect to Norway. Luciani rather relies on the Economic Complexity Index developed at Harvard University, and similarly points 
to some unexpected relativities. Skeptics will point to deficiencies in all of the statistical tools used in these two chapters: indeed, diversification is one of the most elusive characteristics of an economy, depending, as it does, on relative prices and peculiarities of classification. Nevertheless, the simultaneous use of several indicators and their convergence in showing that diversification has in fact taken place is a result to be taken into account. Whether such diversification has happened to a sufficient extent and whether it has occurred in sectors or stages of production that can contribute structurally to economic sustainability, remain open for discussion.

Does this mean that the level of diversification is not a problem? Certainly not, but one should keep in mind that "diversification" is not a panacea as not all diversification is necessarily positive. In Manal Shehabi's opinion, "setting diversification as the key recipe for economic sustainability in resource-rich states appears on face value inadequate and confusing". This is because diversification may take place with the development of activities, which may be commercially viable only contingent to existing conditions and policies, but not necessarily sustainable in the longer run. If such diversification is pursued at large scale, and subsequently locked in, then oil-producing states would find it difficult to be sufficiently adaptable, much like other non-oil producing states with the rise of global value chains.

From what was highlighted in the previous paragraph, it is clear that diversification may very well take place leveraging the comparative advantage in hydrocarbons and integrating upstream and downstream components of hydrocarbon production, pure and simple. In fact, many authors considered this as welcome, rather than optional. Progressively, this may contribute to the creation of a local market for more knowledge-intensive and higher value-added employment. This point is emphasized in particular by Martin Hvidt, who focuses on value chains as the directing principle for diversification: "adding steps of the value chain will imply a diversification of the product, and thus of markets".

this process of product diversification holds significant implications for a diversification of job content, and thus skills levels of the workers undertaking the jobs: The more diversification takes place within the value chain (adding more stages in the production chain), the greater varieties of jobs will be demanded. Generally, the more primary productive activities are pursued, the higher the demand for supporting activities, which implies jobs related to services. And 
service related jobs generally have a higher knowledge content and provide more value added than jobs in 'pure' manufacturing or oil extraction.

Similarly Shehabi writes: "economic specialization based on comparative advantage is not contradictory to that of economic diversification, and that both concepts are relevant to but insufficient for economic sustainability in resource-rich states". In a significant point of convergence, none of our contributing authors believe that diversification away from oil is a decisive factor of sustainability.

\section{Fiscal Sustainability}

In contrast to diversification away from oil, which is relativized in the discussion, the importance of fiscal sustainability is underlined by almost all our authors. The GCC governments remain excessively dependent on oil revenue for the financing of expenditure, and especially current expenditure. Individual authors offer somewhat different and interestingly complementary approaches to this crucially important aspect. Four main theses are proposed:

1. An important distinction must be made between higher- and lowerrent per capita countries within the GCC

2. Contrary to the view that the GCC implicit political pact is rigid, some significant fiscal adjustment has taken place since the $2014 \mathrm{col}-$ lapse in oil prices

3. Reducing dependence on oil income is only possible if a sufficient domestic taxation base is developed, with very significant implications for the development strategy.

4. Less progress has been made in reducing public sector employment and nationalizing employment in the private sector, even though this is an imminent threat to the sustainability of GCC economies (discussed more later).

\subsection{The Difference between Rentiers and Super Rentiers}

The importance of the level of per capita oil rent with respect to the question of sustainability is emphasized especially by Elbadawi and Makdisi, and Malik and Nagesh. Quoting previous research by Elbadawi, the first 
two authors assert that "there is a small group of 12 exorbitantly high oil rent per capita countries that are mostly non-democratic (hereafter HRPC), including the GCC, which seem to defy the fundamental tenets of the received literature that, non-democratic governance affects growth negatively. He finds that there exists a resource rents threshold, beyond which countries might be able to achieve fast growth and civil peace as well as avoid revolt regardless of the prevailing standard in terms of accountable political institutions". In other words, these super-rentiers, which currently in the GCC include Kuwait, Qatar and the United Arab Emirates (UAE) (certainly at least Abu Dhabi), have been able to escape the resource-curse and have sufficient financial resources to survive future social and political challenges.

Malik and Nagesh argue that "based on per-capita hydrocarbon endowments, the GCC countries can be broadly divided into two categories". On the one hand, there are countries with higher hydrocarbon reserves (and production) relative to their populations. They include Kuwait, Qatar and the UAE (Abu Dhabi led). On the other hand, there are hydrocarbonpoorer per capita countries with smaller hydrocarbon reserves (and production) relative to their populations. They include Bahrain, Oman and Saudi Arabia. Within this group, Oman and Bahrain are in relatively weaker positions versus Saudi.

The higher oil rent per capita countries have accumulated large foreign currency reserves, have maintained a budget surplus or small deficit even after the decline in oil prices and enjoy large sovereign funds whose revenue may in the future progressively substitute for a declining oil rent. It is therefore possible to envisage a scenario in which the state in these countries may continue to be financed from revenue directly accruing from abroad, rather than having to rely on domestic taxation. As a result, it can be expected that these countries will continue to implement pro-cyclical policies. These countries also display the highest share of expatriates in the resident population, meaning that the politically relevant share of the total population is small and relatively easy to be catered to. In contrast, in the three remaining members of the GCC, oil rents per capita are smaller either because oil revenue is less generous (Bahrain) or because the national population is much larger (Saudi Arabia) or a combination of both factors (Oman).

Thus, it is clear that the problem of sustainability is of a completely different nature in the two subsets of GCC member countries. For the higher-rent per capita countries, the essential problem is continuing to 
accumulate in their sovereign investment funds and making sure that returns on their international investment are sufficient to meet the fiscal requirements of the state. For the lower-rent countries, the issue of developing a domestic taxation base is inescapable and entails as a corollary, the need to develop competitive activities and sources of value added that the state may tap to raise the required income.

\subsection{Fiscal Adjustment}

A frequently repeated reason for doubting the sustainability of the Gulf economies is that the political order is based on an implicit pact between the rulers and their people that conditions the acceptance of the former on the part of the latter to the continued availability of historically established transfers in the form of employment in the public sector, free services and various consumption subsidies. The presumed rigidity of this implicit social contract is deemed to prevent adjustment and is therefore unsustainable.

The experience of fiscal policy reform since 2014 demonstrates that adjustment is on the contrary possible, at least partially. Adjustment has been sought through reduction of expenditure and, to a more limited extent, the imposition of new fees and taxes. "The initial response by governments was to substantially cut back government expenditure, especially on the capital front" (Malik \& Nagesh). Abandoning or delaying investment projects has traditionally been the easiest step to reduce expenditure quickly, together with delaying payments to enterprises working for the government and implementing public projects-with the subsequent liquidity crisis, which inevitably ensues. But then steps have also been taken to reduce subsidies, especially on energy products.

Subsidies reform is the main focus of the chapter by Tom Moerenhout: "When the oil price plummeted in 2014, GCC revenues collapsed and all governments increased fuel and electricity prices. By doing so, they primarily avoided an even more menacing collapse of state budgets, which could have led to domestic instability". That is not to deny the fact that low fuel prices have justifications: they serve to contain increases in the cost of living, they enhance the competitiveness of energy-intensive industries and they contribute to political stability. But in the long run, adjustment is needed because consumption has grown out of control and endangers the export potential. 
The pace of pricing reforms is a double-edged sword. On the one hand, there is urgency, not only for fiscal adjustment but also because of projected demand growth for oil and electricity in the Middle East and North Africa (MENA) region. This demand growth is substantial and carries large opportunity costs. Not for a small part, this demand growth will be caused by the need for energy-intensive end uses, such as running airconditioning and salt water desalination as a result of climate change effects. On the other hand, however, Moerenhout warns that overly rapid price adjustments for industry might erode the comparative advantage of Gulf countries and complicate efforts to achieve within-sector diversification.

Since 2014, all GCC countries have enacted some reform of the subsidies system. Three countries-notably the UAE, which was the pioneer, Oman and Qatar-have been able to implement gradual but systematic reform, which created regular adjustment mechanisms linked to regional and international price movements. In contrast, Saudi Arabia, Kuwait and Bahrain have resorted to ad hoc adjustments that are not automatic-but the adjustment has nonetheless been very significant. Also important, the adjustments were not rolled back as soon as oil prices increased. Thus, we may conclude that the taboo of untouchable energy prices has been broken, and governments have learned that, under the appropriate conditions, they can impose adjustments to subsidies. Encouragingly, some countries have started with attempts to implement better targeted social welfare measures, such as cash transfers.

Similarly, new fees and taxes have been imposed by almost all of the GCC countries. True, there has been an attempt to increase the fees paid by expatriates rather than nationals, but this is mostly a question of appearances, because the cost of employing expatriates increases, and eventually this is felt in domestic prices paid by nationals. The imposition of fees on the presence of expatriates' family members has led to a wave of returns to their countries of origin, which has in turn translated into a slump in demand for real estate accommodation and a broad range of consumer goods. The net positive effect of such measures for enhancing government revenue is thus relatively limited.

The most important step undertaken in the GCC is the decision to implement a coordinated Value Added Tax (VAT), as detailed in Malik and Nagesh, although not all member countries may respect the engagement in the envisaged time window. The $5 \%$ rate at which the VAT is currently imposed is relatively small, but constitutes a very important 
development, especially from a political point of view. Certainly, VAT is a tax on consumption rather than income, and as such, it has less of a political impact in the relationship between each citizen and the state, but it is nevertheless a tax and may, in due course of time, prompt a request for greater fiscal transparency and accountability, especially if the rate were to increase significantly.

\subsection{Developing a Domestic Taxation Base}

The difficulties experienced in imposing new taxes and diversifying the sources of state revenue point to the need for cultivating a domestic taxation base. This is the central message of Ishac Diwan in his chapter on fiscal sustainability and the labor market in Saudi Arabia. Although the chapter focuses specifically on the Saudi case, the crucial point about the need for developing a domestic tax base is valid for all lower-rent per capita countries; however, for higher-rent per capita states, much depends on whether they will be able to substitute the oil rent with income from international investment, thus dodging the need for diversification of income sources.

Diwan argues that "Expats do create a buffer for the economy, but are unlikely to be part of the tax base". This is because "expats are being paid their reservation wage, and while they can be fired at will, it is not possible to compress their net incomes by much and keep them employed". At the same time, the majority of nationals are government employees, and while they may earn extra income from private sector activities, the resources that may be squeezed out of household budgets by way of VAT or an income tax are perforce limited relative to government expenditure. Finally, corporate taxes are limited by total profits of private corporations, many among which are very small and presumably surviving on a precarious equilibrium.

Hence, the key conclusion and answer to "the question of interest is therefore what growth model can deliver a larger tax base?" is one that supports growth in the private sector and at the same time discourages employment of expatriates and encourages the employment of nationals and an increase in labor productivity, that is, value added per employee.

This crucial conclusion points to the fact that fiscal sustainability is not independent of the chosen growth strategy. Malik and Nagesh concur with this conclusion when they write, "Two factors will be central to boosting fiscal sustainability across the region, in our view: (i) the deepening of the tax base and (ii) lowering the wage composition of government 
spending". Of course, lowering the burden of wages on total government spending means reducing public sector employment and shifting some roles from the public to the private sector. Luciani writes about the need for developing taxation and notes "The need for nurturing a strong base for taxation is the main argument to conclude that economic sustainability eventually requires the consolidation of a competitive and independent private sector".

\section{Sustainability and the Labor Market}

Several of our authors underline the importance of reforming the GCC labor markets for sustainability. There are two opposing views of this issue, depending on whether we focus on high- or low-rent per capita countries. In the former group, dependence on expatriate labor is extreme, and provides an element of flexibility in the face of potential downturn of available rent, which may be said to considerably enhance sustainability. Shehabi writes "the expatriate labor exit offers another key stabilization mechanism of the Kuwaiti economy in the face of the volatility of petroleum revenue". The same can be said of Qatar and Abu Dhabi, although possibly not for the UAE as a whole. In other words, if push comes to shove and the revenues from oil exports and sovereign wealth funds collapse dramatically, these countries are able to send home a large share of their expatriate population. Radical and fast-paced changes would certainly allow for very significant reduction in government expenditure: it would also lead to a collapse of real estate and many businesses, which could also lead to the deterioration of effective standards of living for a part of the national population. That being said, a new equilibrium at a lower ratio of expatriates to nationals could be found without too much affecting the condition of most nationals.

The situation is different for low-rent per capita countries, because the flexibility offered by expatriate workers is proportionately lower (though still high compared to nearly any other producing country in other regions). Comparatively to high-rent GCC countries, the damage deriving from quickly drawing their numbers down would thus be higher. The fiscal equilibrium in these countries is also much more fragile, necessitating, as discussed here, the development of a domestic taxable base which expatriates cannot offer.

Elbadawi and Makdisi point to the importance of productivity: 
growth has been largely driven by factor accumulation in the form of massive investments and even more through large scale utilization of unskilled and semi-skilled labor, mainly drawn from the Indian sub-continent. This growth model has obviously served the GCC well and allowed the building of state-ofthe-art infrastructure at exceptionally low cost of labor. But one major drawback of the GCC growth strategy has been low and even declining total factor as well as labor productivity.

The decline in productivity casts a shadow on the possibility of raising more revenue from domestic sources.

The open door to essentially unlimited importation of expatriate labor bids wages down and discourages nationals from active participation in the labor force.

Huge gains could be made if they were instead encouraged to do so, because Saudi nationals are both grossly underemployed and increasingly well educated, thus increasing the opportunity cost of low participation. To give a sense of the potential gains if national labor was employed more effectively, a simple projection model suggests that with participation rates growing from 40 to 60 percent of the working-age population, and unemployment dropping to its natural rate, non-oil national income would more than double if the additional workers join the non-oil sector at current productivity levels. Improvements in labor productivity would add to this growth rate further. Altogether, it can be estimated that this addition to national wealth is comparable in magnitude to the kingdom's current oil wealth. (Diwan)

Underemployment of nationals is a cause of unsustainability. For Diwan, the issue is closely connected to the prospects for raising domestic taxation:

A path of labor intensive growth leveraged on expat labor can allow for larger taxation of corporate profits, but if it does not manage to increase employment among Saudis, it would require more social spending to preserve social peace, and thus, would not be conducive to correcting the macro-imbalances. On the other hand, growth based on the expansion of Saudi labor would lead to a broader tax base over time

Already now, the GCC is confronted with high unemployment. In earlier work, Tom Moerenhout has pointed to increasing youth unemployment as a potential threat to national security, adding even more pressure 
when considering a poor female labor participation rate. Currently, most GCC countries have around 40\% youth unemployment for 20-24-yearolds, declining to a still sizeable 15\% for 30-34-year-olds. As Martin Hvidt highlights, approximately 500,000 nationals will enter working age each year during the next decade and a half in Gulf countries, exacerbating what is often labeled as a "ticking time bomb". Hence, political stability is directly challenged by the inability to mobilize the domestic workforce and increase its productivity level.

The issue is not simply one of substituting expatriates with nationals. Drawing down the number of expatriates has not so far succeeded in creating an equivalent number of jobs for nationals. Mobilization of the domestic work force can only be achieved through investment to change the capital per worker in the private sector:

The good news is that the education level among young Saudis has risen, which makes it possible for them to occupy jobs at relatively high productivity levels. The bad news, however, is that existing incentives have pushed firms in the private sector to create jobs that require either very low skills (especially in services) or very high skills (especially in the energy sector). To create jobs that are attractive for Saudis, who have mostly mid-level skills, there is therefore a need for structural change in the production methods used by the private sector, in response to changes in factor endowments and prices. (Diwan)

\section{Political Sustainability}

At this juncture, perbaps the most compelling question to ask with regard to development sustainability of the GCC countries would be: in which direction might the political equilibrium in these societies shift as a consequence of the new global oil order? (Elbadawi \& Makdisi)

That is indeed an essential dimension of sustainability, because one cannot expect the needed economic policy adjustments to take place without parallel adjustments in political equilibria. This is especially true of the low-rent per capita countries, where greater reliance on a private sector less dependent on government expenditure and capable of walking on its own legs is a prerequisite of sustainability. In addition, the need to increasingly rely on taxation of domestic value added inevitably raises the issue of accountability and legitimacy of power structures. In other words, the low-rent per capita countries will need to gradually evolve from being pure rentier states to being states whose existence is based on the ability to 
extract a surplus from the domestic economy, which is a key determinant of demand for democratic participation, "No taxation without representation", also in the Persian Gulf. In earlier work, Luciani noted that in the late 1990s, when these states were fiscally challenged after 15 years of low oil prices and growing deficits, it seemed that a national bourgeoisie might emerge and become a significant political actor. Timid yet promising attempts were made in the direction of an enlargement of the political sphere, but following the Arab Spring, all hatches were closed down and authoritarianism has toughened.

Elbadawi and Makdisi analyze the situation using the concepts of limited versus open access order:

the prevailing GCC politico-economic institutional set up might be described as a relatively advanced form of 'limited access order' (LAO), where projection of organized violence is firmly under the incumbent authorities and rents distribution is governed by inter-personal networks, but at the same time adjudication and settlement of disputes among the elites become increasingly formalized through courts and other formal arrangements. It follows that the prospects of significantly lower oil prices under the new global oil order, and the ensuing reductions in rents per capita, might very well push the GCC political equilibrium from an advanced $L A O$ to a fragile state of $L A O$, akin to the one that prevails in some of the populous Arab oil countries. Such unfortunate transition would surely put an end to the GCC's relatively successful development model. On the other hand, it is possible that the path dependence of the political process in some at least of the GCC member countries might create some positive inertia, leading them to develop into an impersonal 'open access order' (OAO), whereby the society graduates to a stable institutional equilibrium.

Unfortunately, all evidence is in the direction of "fragilization" of LAO rather than movement toward OAO. This is all the more so since at the regional level, conflicts and tensions have been increasing systematically, and the GCC countries have implicated themselves deeper and deeper into such conflicts and proxy wars. With the row between Saudi Arabia and the UAE on one side and Qatar on the opposite side, the very significance of the GCC is also questioned. As Luciani has noted in an earlier work, regional disaggregation is a problem for sustainability, because it hinders the emergence of economic activities that are regional in nature and damages the development prospects of all countries in MENA.

As far as the social contract goes, Moerenhout has argued in an earlier work that the effects from the fragilization of LAO and the discontent 
with austerity measures can potentially be countered by the rapid development of more targeted social safety nets. As cash transfers can keep rentier state dynamics intact in the short term, they appear as the best option to compensate for loss of household welfare. However, they are not a panacea to resolve the structural deficiencies of GCC states. The success of cash transfers will ultimately depend on their design and implementation, as well as on the introduction of complementary short-term mitigation measures and longer-term adjustments in, among others, the labor market.

\section{Can the GCC Economies Be Sustainable?}

The discussion of sustainability that is presented in this book may not offer a definitive definition of the term, but nevertheless converges on some useful policy indications.

Sustainability does not necessarily mean diversification, and especially not diversification away from hydrocarbons. Rather, the comparative advantage in hydrocarbon production must be leveraged to integrate upstream and downstream in the value chain, while at the same time defending the acceptability of hydrocarbons through the decarbonization of their production, development of non-fuel uses and carbon capture and sequestration. At the same time, increasing reliance on renewable and other non-carbon energy sources must be pursued, as well as greater energy efficiency.

Diversification contributes to sustainability if it is accompanied by the emergence of a private sector less dependent on government expenditure and capable of offering better, more productive jobs to the national workforce. Reliance on expatriate labor must be reduced and taxes progressively introduced to pay for current public sector expenditure.

For the high-rent per capita countries, a scenario of growing revenue from international financial placements (sovereign wealth funds) complementing declining oil revenue cannot be excluded. The success of such a strategy, based on consolidation of, rather than transition from, the rentier nature of the state, cannot a priori be excluded. The outcome very much depends on the ability to invest wisely and attain a sufficiently high rate of return-not something that is guaranteed at this stage. It also very likely depends on a process of demographic retrenching, shedding a large portion of the expatriate population and raising the ratio of nationals to expatriates in the resident population. It is not inconceivable that these states may survive as patrimonial monarchies. 
For low-rent per capita countries, including Bahrain, Oman and Saudi Arabia, a similar strategy is not possible. To the extent that the state will attempt to preserve its rentier nature through the accumulation of a large sovereign wealth fund (a possibility which in practice may be open to Saudi Arabia only), it will need to increasingly erode the benefits extended to the national population. In the absence of improved employment opportunities in the private sector, hidden or overt unemployment is already a growing problem, and discontent will inevitably ensue. Sustainability will be threatened not so much by immediate fiscal and/or trade imbalances, but by the inability to adapt institutions to the requirements of a sustainable economy. The status quo may be preserved through repression, possibly even for a long time, but the sustainability challenge will have been lost.

Open Access This chapter is licensed under the terms of the Creative Commons Attribution-NonCommercial-NoDerivatives 4.0 International License (http:// creativecommons.org/licenses/by-nc-nd/4.0/), which permits any noncommercial use, sharing, distribution and reproduction in any medium or format, as long as you give appropriate credit to the original author(s) and the source, provide a link to the Creative Commons licence and indicate if you modified the licensed material. You do not have permission under this license to share adapted material derived from this chapter or parts of it.

The images or other third party material in this chapter are included in the chapter's Creative Commons licence, unless indicated otherwise in a credit line to the material. If material is not included in the chapter's Creative Commons licence and your intended use is not permitted by statutory regulation or exceeds the permitted use, you will need to obtain permission directly from the copyright holder. 